\title{
Penerapan Universal Precuation Dalam Pencegahan Infeksi Nosokomial di RSUD Toto Kabila
}

\author{
Rhein Djunaid, Suratni Hamzah \\ Fakultas Olahraga dan Kesehatan Universitas Negeri Gorontalo \\ E-Mail: reindjunai@yahoo.com
}

\begin{abstract}
ABSTRAK
Infeksi nosokomial merupakan masalah yang besar di setiap rumah sakit. Infeksi dapat terjadi antar pasien, dari pasien ke petugas, dari petugas ke petugas, dari petugas ke pasien dan antar petugas. Infeksi di rumah sakit lebih dikenal sebagai infeksi nosokomial. Kasus infeksi nosokomial terjadi hampir di seluruh negara terutama di negara miskin dan berkembang termasuk Indonesia. Tujuan penelitian Mengetahui Penerapan Universal Precaution dalam mencegah Infeksi Nosokomial di RSUD Toto Kabila. Desain yang digunakan studi deskriptif. Jumlah sampel 130 responden dengan tehnik sampel yang di gunakan adalah Total Sampling. umur responden lebih banyak yang berusia 31-40 tahun yaitu 54.6\%, berjenis kelamin perempuan sebesar 98 responden. berpendidikan Ners sebanyak 67 responden. Lama kerja $>5$ tahun sebesar 79 responden . Yang tidak melakukan cuci tangan handwash 89 responden. menggunakan cuci tangan memakai hundrub sebanyak 70 responden. Saran: seluruh perawat mencuci tangan sesuai SOP dalam rangka mencegah infeksi nosokomial.
\end{abstract}

Kata kunci: universal precaution, infeksi nosokomial

\begin{abstract}
Nosocomial infection (HAIs) has been considered as the biggest problem occurred in the hospital. The research applied desscriptive study. Sampling was determined to 130 respondents through total sampling. Range of age was 31-40 years old or 54\% female respondents were 98 or $75.4 \%$, Ners qualification was 67 respondents or $51,5 \%$. Lenght of work above 5 year was 79 respondents or $60,8 \%$. Hand washing with handrub was 70 respondents or $69,2 \%$. Finally, it is recomended to all nurses to do hand washing based on SOP in order to prevent nosocomial infection.
\end{abstract}

Keywords: universal precaution, nosocomial infection

\section{PENDAHULUAN}

Infeksi nosokomial (HAIs)

merupakan masalah yang besar di setiap rumah sakit. Penelitian yang dilakukan oleh WHO menunjukkan bahwa prevalensi HAIS berkisar $8,7 \%$ dari 55 rumah sakit di 14 negara yang berasal dari Eropa, Timur Tengah, Asia Tenggara dan Pasifik tetap menunjukan adanya infeksi nosokomial di Asia Tenggara adalah $10 \%$ (Nursalam, 2015).

Infeksi di rumah sakit ini dapat disebabkan oleh mikroorganisme yang didapat dari orang lain (cross infection) atau disebabkan oleh flora normal dari pasien itu sendiri (endogenous infection). Bakteri ini berkembang di lingkungan rumah sakit yang berasal dari air, udara, lantai, makanan serta alat-alat medis maupun non medis. Sumber penularan bisa melalui tangan petugas kesehatan, jarum injeksi, kateter, kasa pembalut atau perban dan karena penanganan yang kurang tepat dalam menangani luka. Selain pasien, infeksi nosokomial ini juga dapat mengenai petugas rumah sakit yang berhubungan langsung dengan pasien maupun penunggu dan para pengunjung pasien (Nursalam, 2015).

Infeksi terkait sarana pelayanan kesehatan adalah tantangan yang serius bagi rumah sakit karena hal tersebut dapat menyebabkan kematian, baik langsung maupun tidak langsung serta menjadikan 
pasien dirawat lebih lama dan memakan biaya lebih mahal. Semakin tingginya kasus infeksi yang didapat dari rumah sakit, hendaknya pihak rumah sakit menyusun program upaya pengendalian infeksi yang serius. Salah satu strategi yang bermanfaat dalam pengendalian infeksi nosokomial adalah peningkatan kemampuan petugas kesehatan dalam metode universal precautions (Depkes, 2010).

Universal precautions merupakan suatu pedoman yang ditetapkan oleh the Centers for Desease Control and Prevention (CDC) dan the Occupational Safety and Health Administration (OSHA). Pedoman ini untuk mencegah transmisi dari berbagai penyakit yang ditularkan melalui darah di lingkungan fasilitas pelayanan kesehatan. Tindakan universal precautions meliputi pengelolaan alat kesehatan, cuci tangan untuk mencegah infeksi silang, dan penggunaan alat pelindung diri misalnya kaca mata pelindung, masker muka, sarung tangan dan celemek untuk mencegah kemungkinan percikan dari tubuh.

Universal precautions diharapkan akan mendapat perlindungan maksimal dari infeksi yang telah diagnosis maupun yang belum diketahui. Universal precautions juga berguna untuk menurunkan transmisi infeksi saluran kemih, infeksi luka operasi, pneumonia, sepsis, dan phlebitis pada individu dan tenaga kesehatan, sehingga dapat diberlakukan di semua unit pelayanan kesehatan maupun perorangan (Nasronudin, 2007).

Universal precautions tidak hanya melindungi petugas dari risiko terpajan oleh infeksi namun juga melindungi klien yang mempunyai kecenderungan rentan terhadap segala infeksi yang mungkin terbawa oleh petugas (Kurniawati \& Nursalam, 2007). Usaha pencegahan dan pengendalian penyakit infeksi antara lain dapat dilakukan dengan meningkatkan perilaku universal precautions bagi perawat. Tindakan universal precautions diperlukan kemampuan perawat untuk mencegah infeksi, ditunjang oleh sarana dan prasarana, serta Standar Operasional Prosedur (SOP) yang mengatur langkahlangkah tindakan universal precautions (Kurniawati \& Nursalam, 2007). Survey awal yang di lakukan oleh peneliti bahwa terdapat 56 klien yang terdiagnosa infeksi sekunder oleh dokter spesialis pada tahun 2016, dari survey tersebut di dapatkan bahwa penerapan universal precautions belum berjalan dengan baik. Fenomena ini menjadi pertanyaan apakah di karenakan penerapan universal precautions bagi perawat masih kurang atau ada faktor lain.

Berdasarkan hasil wawancara pada petugas di RSUD Toto Kabila pada hari sabtu tanggal 25 Oktober 2017 dari 10 perawat 6 perawat mengatakan kebanyakan cuci tangan setelah melakukan tindakan dan 4 orang perawat mengatakan kadang-kadang cuci tangan sebelum dan sesudah melakukan tindakan.

Penelitian ini dilakukan di RSUD Toto Kabila, pada tanggal 23 November sampai dengan 7 Desember tahun 2017. Desain penelitian yang digunakan adalah studi deskriptif yang mempunyai variabel tunggal yaitu penerapan universal precaution dalam mencegah infeksi nosokomial. Sesuai dengan data sekunder yang diperoleh menyebutkan bahwa 
jumlah perawat pelaksana yang ada di Rumah Sakit Toto Kabila Gorontalo adalah berjumlah 130 orang perawat pelaksana. Pada tahap ini dilakukan pengolahan data terhadap data yang sudah dimasukkan kedalam program computer, sehingga dihasilkan informasi yang dapat digunakan untuk menjawab pertanyaan penelitian. Distribusi frekwensi data demografi,variabel dianalisis dengan menggunakan statistic deksriptif. Tujuannya adalah untuk mendapatkan gambaran tentang sebaran dari masingmasing variable.

Lembar persetujuan akan diberikan sebelum penelitian dilaksanakan kepada klien yang akan diteliti dengan tujuan agar responden mengetahui maksud dan tujuan penelitian

\section{HASIL}

Tabel 1. Distribusi responden berdasarkan pendidikan

\begin{tabular}{lll}
\hline Pendidikan & $\begin{array}{l}\text { Frekuensi } \\
(\mathrm{N})\end{array}$ & $\begin{array}{l}\text { Presentase } \\
(\%)\end{array}$ \\
\hline DIII & 63 & 48.5 \\
S1 Ners & 67 & 51.5 \\
Total & 130 & 100 \\
\hline
\end{tabular}

Tabel 2. Distribusi responden berdasarkan pendidikan

\begin{tabular}{lll}
\hline Lama Kerja & $\begin{array}{l}\text { Frekuensi } \\
(\mathrm{N})\end{array}$ & $\begin{array}{l}\text { Presentase } \\
(\%)\end{array}$ \\
\hline$<5$ tahun & 51 & 39.2 \\
$>5$ tahun & 79 & 60.8 \\
Total & 130 & 100 \\
\hline
\end{tabular}

Tabel 3. Penerapan handwash

\begin{tabular}{lll}
\hline Handwash & $\begin{array}{l}\text { Frekuensi } \\
(\mathrm{N})\end{array}$ & $\begin{array}{l}\text { Presentase } \\
(\%)\end{array}$ \\
\hline Dilakukan & 40 & 30.8 \\
Tidak dilakukan & 89 & 69.2 \\
Total & 130 & 100 \\
\hline
\end{tabular}

Tabel 4. Penerapan handrub

\begin{tabular}{lll} 
Handrub & $\begin{array}{l}\text { Frekuensi } \\
(\mathrm{N})\end{array}$ & $\begin{array}{l}\text { Presentase } \\
(\%)\end{array}$ \\
\hline Dilakukan & 70 & 69.2 \\
Tidak dilakukan & 60 & 30.8 \\
Total & 130 & 100 \\
\hline
\end{tabular}

\section{PEMBAHASAN}

\section{Penerapan handrub di RSUD Toto Kabila}

Hasil analisis dengan menggunakan frekuensi tabel maka didapatkan data bahwa untuk responden yang menggunakan cuci tangan memakai hundrub sebanyak (84\%) Sedangkan yang tidak menggunakan cuci tangan memakai hundrub (16\%). Mencuci tangan adalah kegiatan membersihkan bagian telapak, punggung tangan dan jari agar bersih dari kotoran dan membunuh kuman penyebab penyakit. Mencuci tangan dapat mengurangi pemindahan mikroba ke pasien dan menghambat pertumbuhan mikroorganisme pada kuku, tangan, dan lengan. Mencuci tangan telah sejak lama dipraktikan untuk memutus rantai transmisi sehingga infeksi nosokomial dapat di cegah.

Dari hasil penelitian yang telah dilaksanakan Di RSUD Toto Kabila Sebagian besar pasien mencuci tangan memakai hundrub karena berdasarkan hasil observasi penelitianPenerapan cuci tangan pada perawat tergolong baik karena didukung oleh kesadaran perawat itu sendiri dalam melindungi diri dan pasien dari bahan infeksius serta kesadaran dalam menjalankan SOP yang benar. Kebiasaan mencuci tangan perawat di rumah sakit, merupakan perilaku mendasar dalam upaya pencegahan cross infection (infeksi silang). Pengetahuan merupakan elemen 
yang sangat penting untuk terbentuknya tindakan seseorang. Perawat juga harus memiliki pengetahuan tentang cuci tangan dengan benar sebagai upaya pencegahan infeksi nosokomial di rumah sakit sehingga dapat meningkatkan kualitas pelayanan. Penelitian yang telah dilakukan oleh Girou et all (2002) dan parienti et all (2002) menambah bukti bahwa menggosok tangan menggunakan cairan yang berbahan alkohol lebih efektif di bandingkan metode kebersihan standar yaitu mencuci tangan menggunakan air dan sabun.

Penelitian yang dilakukan ahli infeksi JM Boyce MD dan Didier Pittet MD (2002) juga mengungkapkan, kegagalan menjalankan kebersihan tangan merupakan penyebab utama infeksi nosokomial (infeksi yang terjadi akibat pelayanan kesehatan di rumah sakit setelah 48 jam atau lebih). Untuk itu, salah satu cara memutus rantai penularan infeksi adalah mengupayakan kebersihan tangan . Selain wastafel beserta sabun cuci tangan dan kertas tisu, saat ini rumah sakit ratarata sudah menyediakan alkohol handrub, sejenis cairan berbahan dasar alkohol plus gliserin sebagai pelembut. Cairan pembunuh kuman (antiseptik) ini umumnya dikemas praktis di dalam botol atau dispenser mini dan diletakkan di lokasi-lokasi penting serta mudah diraih seperti di ruang rawat pasien, kamar bedah, ruang ICU, ruang praktik dokter dan ruang tunggu pasien.

Para petugas medis seperti dokter dan perawat juga banyak yang mengantongi handrub kemanapun. Menurut Endang, alkohol handrub merupakan fasilitas cuci tangan inadekuat yang cepat dan aman untuk menurunkan flora kulit. Namun, ia menekankan bahwasanya alkohol handrub bukanlah pengganti cuci tangan. Boleh saja menggunakan handrub hingga 5-6 kali, tapi selepas itu tetap harus mencuci tangan dengan sabun dan air mengalir (bukan air di dalam waskom). Pemakaian handrub hanya ditujukan untuk kondisi darurat dimana fasilitas cuci tangan seperti wastafel sulit dijangkau. Untuk tangan yang kotor, ya tetap harus pakai air dan sabun.

Rinaldi (2014) dari Laboratorium Mikrobiologi dan Patologi Klinik RS Persahabatan, mengemukakan, alkohol handrub memiliki keunggulan dalam hal kecepatan dan praktis. Bila cuci tangan pakai sabun (CTPS) dan air mengalir memakan waktu 60-90 detik, handrub cukup 30 detik saja. Selain persoalan perilaku dan fasilitas, waktu adalah faktor utama yang menjadikan orang malas cuci tangan pakai sabun dan air. Padahal, CTPS adalah metode terbaik.

\section{Penerapan handwash di RSUD Toto Kabila}

Hasil analisis dengan menggunakan frekuensi tabel maka didapatkan data bahwa untuk responden yang menggunakan cuci tangan menggunakan handwash sebanyak 40 responden $(30,8 \%)$, Sedangkan yang cuci tangan memakai hundwash sebanyak 90 responden $(69,2 \%)$.

Dari hasil penelitian yang telah dilaksanakan Di RSUD Toto Kabila Sebagian besar tidak mencuci tangan handwash karena berdasarkan hasil observasi penelitianbahwa mencuci tangan dengan memakai sabun dan air memakan waktu 60-80 detik dan memerlukan waktu 
untuk mengeringkannya (Mathai,et all.2010). Dengan memakai sabun banyak kelemahan yang di temukan yaitu dilaporkan kasus iritasi dan kekeringan pada kulit, kesulitan mengakses perlengkapan cuci tangan, penigkatan kesibukan karena mencuci tangan cukup memakan waktu. Penggunaan sabun juga tidak membunuh organisme hanya menghambat dan mengurangi jumlah mikroorganisme.

Cuci tangan pakai sabun tidak bisa digantikan oleh handrub karena materi organik dan kotoran tertentu hanya bisa hilang setelah memakai sabun dan diguyur air mengalir, sabun kesehatan antiseptik memiliki daya bunuh kuman terbaik dibanding handrub dan sabun biasa. Sabun yang dipakai sebaiknya sabun cair. Kalaupun memakai sabun batangan, letakkan di tempat sabun yang bagian bawahnya berlubang supaya tetap kering. Tempat sabun ini juga harus rajin dibersihkan. Kalau kotor atau basah, bisabisa tumbuh pseudomonas. Untuk itulah membiasakan cuci tangan sejak dini pada anak anak sangat penting dilakukan. Kesadaran menjaga kebersihan yang diawali dari cuci tangan perlu ditumbuhkan sejak mereka masih kecil. Apalagi dengan mencuci tangan bisa mencegah masuknya bakteri dan kuman ke dalam tubuh.

\section{SIMPULAN}

Penerapan handwash di RSUD Toto Kabila yang tidak melakukan cuci tangan 90 responden $(69,2 \%)$ yang melakukan cuci tangan 40 responden (30.8\%), sedangkan untuk penerapan hundrub responden $(69.2 \%)$, yang tidak melakukan 60 responden $(30.8 \%)$.

\section{DAFTAR PUSTAKA}

Arikunto. S. (2010). Prosedur Penelitian:suatu pendekatan praktek, PT Rineka Cipta, Jakarta.

Darmani, (2008) .infeksi Nosokomial problematika dan pengendaliannya.Jakarta:s alemba

Depkes(2010). Pedoman Manajemen kesehatan dan keselamatan kerja di rumah sakit. Jakarta

Laxminarayan, (2010). Methicilin Resistant Staphylococcus aureus.

MoenirH.A.S, (2010), Manajemen Pelayanan Umum di Indonesia, Jakarta: Bumi Aksara.

Nasrodin (2007). Penyakit infeksi di Indonesia. Jakarta: Salemba Medika.

Nursalam (2015). Manajemen

Keperawatan: Aplikasi Dalam Praktek Keperawatan

Profesional. Jakarta: Salemba Medica.

WHO. (2008), Standard Precautions in

Health http://www.who.int/csr/resources/p ublications/4epr-am2.pdf. hal 63. 